\title{
História da educação do tempo presente: bases teórico-metodológicas
}

Afonso Celso Scocuglia

Professor da Universidade Federal da Paraíba Pós-doutorado em Ciências da Educação pela Université Lumière Lyon,

França

\section{Resumo}

Neste trabalho, nosso objetivo foi expor a relevância das bases teórico-metodológicas da história da educação do tempo presente e desta para a pesquisa histórico-educacional. Partimos dos alicerces da história do tempo presente, destacando alguns conceitos construtores desse campo oriundos de autores como Rémond, Bédarida e Chartier, entre outros. A seguir, trabalhamos os avanços e os desafios enfrentados pelos pesquisadores desse campo. As fontes disponíveis para as pesquisa da história da educação do tempo presente foram destacadas, argumentando que a abundância delas e a proximidade do pesquisador em relação ao tempo da sua ação não facilitam a pesquisa e não diminuem sua necessária rigorosidade. Os alicerces da história do tempo presente, os desafios, os avanços, suas fontes abundantes e sua aplicação rigorosa constroem uma nova epistemologia para a história da educação, marcada pelas incertezas que referenciam a centralidade da problematização na pesquisa histórica. Toda essa argumentação é reforçada pela idéia originária de que a educação, como uma prática social, exige de seus pesquisadores a consecução dos depoimentos orais, das informações e de todos os tipos de documentação oriundas dos sujeitos que a fizeram/fazem.

Palavras-chave: Educação; História; Tempo.

\section{Résumé}

Dans ce travail, nous avons eu pour objectif de montrer et de défendre l'importance de l'histoire de l'éducation du temps présent pour la recherche historico-éducative. Nous avons pris comme point de départ les fondements de l'histoire du temps présent, en soulignant quelques concepts constructeurs de ce champ créés par des auteurs tels que Rémond, Bédarida et Chartier, entre autres. Ensuite, nous avons analysé les avancements et les enjeux affrontés par les chercheurs de ce domaine. Les sources disponibles pour les recherches sur l'histoire de l'éducation du temps présent ont été mises en relief, en considérant le fait que leur abondance et la proximité du chercheur par rapport au moment de son action ne facilitent pas son travail ni en diminuent la rigueur nécessaire. Les fondements de l'histoire du temps présent, les enjeux, les avancements, ses sources abondantes et son application rigoureuse construisent une nouvelle épistémologie pour l'histoire de l'éducation marquée par les incertitudes qui fondent la centralité de la problématisation dans la recherche historique. Toute cette argumentation est renforcée par l'idée originaire selon laquelle l'éducation, en tant que pratique sociale, exige de ses chercheurs la consécution des témoignages oraux, des informations ainsi que de toute sorte de documents provenant des sujets qui l'ont faite/la font..

Mots-clés: Éducation; Histoire; Temps. 


\section{Introdução}

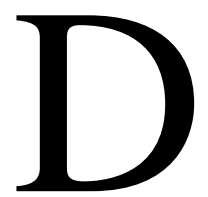

urante muito tempo foi aceita a argumentação de que a “matéria prima” da pesquisa histórica concentrava-se exclusivamente no passado. O presente, a contemporaneidade, não faria parte da história. Esta concepção ainda norteia muitas pesquisas e o "tempo presente" é tratado como próprio da antropologia, da sociologia, da psicologia etc. e, não, da história.

No entanto, especialmente a partir das argumentações, das pesquisas e das teses construídas nos múltiplos caminhos da "nouvelle histoire", a separação passado/presente e a exclusão do presente do rol da pesquisa histórica foram gradativamente abaladas e refutadas em sua inteireza, não mais resistindo a uma análise crítica cuidadosa e isenta.

Aprendemos que: (a) “oposição presente/passado não é um dado natural, mas, sim, uma construção”; (b) “a visão de que o mesmo passado muda segundo as épocas e que o historiador está submetido ao tempo em que vive”; (c) “o interesse do passado está em esclarecer o presente; o passado é atingido a partir do presente” (método regressivo de Bloch) e (d) “a história não só deve permitir compreender o 'presente pelo passado'atitude tradicional - mas também compreender 'o passado pelo presente”' (Le Goff, 1992, p.13-24).

Com efeito, se aceitarmos a inseparabilidade do presente e do passado e se entendermos que todo historiador pesquisa o passado a partir do seu tempo (que é o presente) e do seu espaço social (hoje), poderemos aceitar que história (da educação) do tempo presente modifica a história (da educação) do tempo passado! E, portanto, a história da educação do tempo presente é determinante das descobertas da história da educação do passado vivo. Em outras palavras, podemos argumentar que a história da educação do tempo presente não é só importante em si mesma, mas é também determinante do conhecimento do passado. As histórias da educação do tempo presente reconstroem as histórias da educação do passado sendo, 
portanto, fundamentais para a história e a historiografia da educação - do passado, do presente e da projeção do futuro. Por isso, o aprofundamento das pesquisas da história da educação do tempo presente é de suma importância.

Este trabalho pretende, precisamente, defender a relevância práticoteórica da história da educação do tempo presente, ressaltando os alicerces da história do tempo presente, os avanços e desafios dos pesquisadores e as fontes construtoras desse campo (especialmente, as orais) que instituem uma nova epistemologia da história da educação.

\section{História do tempo presente}

Na atualidade, a importância da história vem sendo enfatizada, mais e mais, observando-se sua vivacidade no crescente impacto sobre o cotidiano das pessoas por meio do jornalismo instantâneo e de pesquisa, da mídia em geral, da internet e das novas tecnologias da informação. E, “após um período em que a epistemologia privilegiava a continuidade, a constância, as estruturas, nossos contemporâneos redescobriram, graças ao fato e à atualidade, a importância da história. A atualidade nos persegue, não nos poupa: há uma demanda social e disso somos testemunhas” (Rémond, 1996, p.206).

Ademais, as últimas décadas do Século XX nos trouxeram tantas e tão profundas mudanças que a necessidade de mergulhar na história do tempo presente, para além da história do passado, se fez obrigatória para compreender o nosso tempo e, nele, nossas vidas. Há praticamente consenso de que a história nunca se modificou tanto e tão rapidamente quanto na segunda metade do século passado. Talvez, como nunca, a necessidade ontológica de saber quem somos, de onde viemos e para onde vamos prosseguir tenha se concentrado tanto no nosso presente. E compreender o presente é fundamental para podermos compreender o passado, pois partimos sempre dele para reconstruir o passado. Não se trata de apostar no presenteísmo e, sim, de argumentar sobre o somatório de créditos à história 
do tempo presente tanto em si como para a sua importância para a pesquisa histórica, precisamente porque o tempo presente não está se fazendo em consonância com os padrões de continuidade e as rígidas estruturas previstas teoricamente. Os fragmentos de um mundo que buscou a felicidade de uma vida minimamente digna para a sua grande população, seja pelos capitalismos ou pelos socialismos, demonstram seu fracasso cabal. As previsibilidades e as inexorabilidades ditadas pelas teorias que se insuflaram como verdadeiras ideologias assistem à débâcle contínua do determinismo enquanto prática e enquanto teoria. Podemos dizer que a pesquisa histórica necessita contar com a história do tempo presente, como nunca, porque o atual presente modifica e impacta o conhecimento do passado de maneira ímpar seja quanto à abundância de fontes, seja quanto à própria reinvenção da história e da historiografia. Da mesma forma, aceitamos essa argumentação para a pesquisa histórica da educação.

No entanto, ao pesquisarmos o tempo presente e dele partirmos regressivamente em busca de outras reconstruções históricas, cabe uma atenção especial quanto ao argumento de estar implícita maior ou menor facilidade teórico-metodológica. A pesquisa da história da educação do tempo presente exige "rigor teórico-metodológico igual ou superior à história de outros períodos, enfatizando a disciplina, a probidade e a busca constante e ética da verdade” (ibidem, p.209). Ademais, como pesquisadores nunca neutros, mergulhados numa "atualidade que nos persegue” e nos intima a desvendá-la para podermos caminhar para o passado, somos "responsáveis na pesquisa da verdade objetiva sobre o tempo presente” (ibidem).

Rémond (1996) identifica ainda três principais feixes de questões sobre a história do tempo presente, com conseqüências visíveis também para o campo educacional. O primeiro feixe se refere à sua validade e especificidade/distinção em relação às outras construções históricas. Seria a história do tempo presente (incluindo a educacional) uma história como as outras ou seria uma história distinta? Seus métodos e suas problemáticas seriam diferentes da história do passado? E sua proximidade em relação ao 
pesquisador, colabora, atrapalha ou invalida a pesquisa histórica? Fundamental perguntar: é preciso deixar o tempo presente passar para, aí sim, constituir objeto da pesquisa histórica?

Tentando responder algumas dessas questões podemos afirmar que: não há nenhuma razão para considerarmos a história do tempo presente como uma "outra história" desprovida dos métodos, dos procedimentos de pesquisa e da teoria que foi construída até hoje pelos historiadores em geral. Se sua proximidade em relação ao historiador, por um lado, deve alertar para as vigilâncias necessárias em relação aos perigos de pesquisar um tempo que se vive, que nos impacta e que ajudamos a construir, de outro lado nos oferece uma abundância de fontes até então desconhecidas ou não utilizadas. No caso da história da educação, precisamos ressaltar os depoimentos orais e outras fontes que nos aproximam, mais e mais, do fazer educacional, do que se passa no interior da sala de aula, das relações educador-educando, dos jogos de poderes embutidos em todo processo educacional, enfim, do cotidiano educacional que só pode ser completamente reconstruído com a contribuição dos atores/sujeitos do processo educacional que é essencialmente prático.

Podemos admitir, assim, que se a história do tempo presente reconstrói a história (tradicionalmente pensada como “do passado”) e nos atira e instiga em direções fecundas, inclusive no sentido de repensarmos nossos conceitos de história, no campo da pesquisa histórica da educação o tempo presente nos permite buscar o que os outros períodos impedem: os sujeitos que fizeram essa história, que só existe concreta e completamente no seu dia-a-dia, viva e com seus sujeitos vivos.

No segundo feixe de questões, destacamos a argumentação de que, se o essencial é precisamente a duração, necessário se faz delimitar o campo da história do tempo presente, já que não se trata da história do instante e, sim, de uma história da proximidade, implicando uma duração. Mas, a rigor, onde começa a história do tempo presente? Qual a sua unidade de tempo? Quais critérios definem seu início? Precisamos esperar a abertura dos 
arquivos? Os fenômenos estudados devem ser fenômenos consumados?

Respondendo essas questões, Rémond (1996) coloca que os

Historiadores do tempo presente precisam rever continuamente a delimitação do seu campo de pesquisas. Por um deslocamento continuo e ininterrupto, um problema, um assunto ou um tema que definia seus objetos retira-se do campo, cai em uma história que não é mais do tempo presente. E como resultado da aceleração, que nos fez ver em dois ou três anos o cenário transformar-se, maioria dos temas que estavam no cerne da investigação e da reflexão da história do tempo presente de repente envelhece e passa à condição de objeto do passado: a Guerra Fria, o comunismo, a descolonização. Conseqüentemente, os historiadores do tempo presente devem estar atentos às mudanças, acolher novos temas, dar provas de imaginação (p.207-208).

Por outro prisma, o terceiro feixe de questões nos remete às conseqüências da valorização da história do tempo presente para a história em geral e correspondentemente nos interessa compreender como a educação do tempo presente impacta e reinventa a educação ao longo do tempo passado.

A princípio, um efeito devastador já foi sentido, ou seja, deve-se recorrer a outras fontes e o arquivo escrito perdeu seu caráter de determinante exclusividade na pesquisa histórica e, pelos argumentos antes apresentados, impacta a pesquisa histórico-educacional de maneira ímpar, a partir da relevância das fontes orais, por exemplo. Neste sentido, se faz imperioso estender a crítica aos depoimentos, além de percebermos a fragilidade das nossas descobertas históricas e, principalmente, na relação saber-poder, entendermos que história não nos pertence e que cada indivíduo e cada grupo têm direitos sobre sua história e sua verdade.

Ainda neste caminho, percebemos a principal diferença do pesquisador do tempo presente em relação aos demais ao se confrontar com a atualidade: seu olhar tem raio curto, concentra-se nos detalhes e se diferencia dos que trabalham com as longas durações nas quais o que se repete e se consolida facilita o entendimento dos fenômenos mais estáveis e constantes (estruturais). Por seu turno, a história (inclusive da educação) do 
tempo presente "evoca a importância da contingência e do fato: a história é feita de surpresas, mais de surpresas do que de ardis” (ibidem, p.208-209).

E, diante desta argumentação,

Freqüentar a história do tempo presente talvez seja uma boa precaução, o meio mais seguro de nos resguardarmos da tentação que sempre nos espreita de introduzir no relato do passado uma racionalidade que não podia estar lá. A operação indispensável de tornar inteligível não deve exercer-se em detrimento da complexidade das situações e da ambivalência dos comportamentos. A história do tempo presente é um bom remédio contra a racionalização "a posteriori", contra as ilusões de ótica que a distância e o afastamento podem gerar (Rémond, ibidem, p.209).

Certamente, aqui, assalta-nos uma indagação para o debate: os historiadores do tempo presente podem/devem trabalhar em conjunto com os historiadores do tempo passado? Ou seja, o raio curto do olhar detalhista de um pode/deve ser associado à visão da longa duração estruturante do outro?

\section{Os avanços e os desafios dos historiadores do tempo presente}

Neste segmento destacamos alguns avanços e, também, os desafios das pesquisas do tempo presente em relação aos historiadores de outros períodos. Conforme Chartier (1996), a pesquisa histórica do tempo presente "não é a busca desesperada de almas mortas, mas um encontro com seres de carne e osso que são contemporâneos daquele que lhes narra as vidas” e, ademais, ele "é o único que pode superar a descontinuidade fundamental que costuma existir entre o aparato intelectual, afetivo e psíquico do historiador e o dos homens e mulheres cujas histórias ele escreve” (p.215).

Com efeito, além de contar com recursos documentais abundantes, renováveis e que parecem não se esgotar, mas, ao contrário, se multiplicar, estes historiadores podem construir seus próprios arquivos.

No entanto, ao passar da estrutura/conjuntura para as 
representações/práticas (como propõe Chartier, 1990) ou ao tentar trabalhálas em conjunto, a multiplicação das questões implica, mesmo com a abundância de fontes, em grandes desafios para respondê-las. Mas, a capacidade de construir arquivos e metodologias adequados às suas novas indagações parece lhes proporcionar a possibilidade de concreta de superação desses desafios multiplicados. Entre esses desafios, a própria abundância das fontes, somada às preocupações e vigilâncias epistemológicas, denota os problemas a serem enfrentados com a proximidade do seu objeto pesquisado.

Do prisma das conseqüências da crescente importância atribuída à história do tempo presente podemos reafirmar com Chartier que "essa história inventou um grande tema, agora compartilhado por todos os historiadores, seja qual o for o período de sua predileção: o estudo da presença incorporada do passado no presente das sociedades e, logo, na configuração social das classes, dos grupos e das comunidades que as constituem” (ibidem, p.216).

Ainda conforme Chartier, a história do tempo presente articula “a parte voluntária e consciente da ação dos homens e os fatores ignorados que a circunscrevem e a limitam” (ibidem, p.216). Ora, esta parte voluntária e consciente em referência compõe o cotidiano dos processos educativos de uma maneira iniludível. Está presente nas ações de reciprocidade educadoreducando, professor-aluno, bem como nas práticas de gestão, de planejamento, da práxis curricular. Para esse autor, a argumentação se torna fundamental, pois "os trabalhos mais argutos dos historiadores contemporâneos (...) são aqueles que se recusando a identificar a história a essa filosofia mutilante do sujeito e da consciência, inserem as escolhas, os compromissos ou as decisões mais voluntárias nas circunstâncias que os tornaram cogitáveis e, logo, possíveis, bem como nos determinantes que os regem e comandam”. (ibidem, p.217).

Neste sentido, a história da educação do tempo presente também adquire importância decisiva quando se apóia nas descobertas das ciências 
sociais contemporâneas refletindo sobre as internalizações do social por parte dos indivíduos que possuem uma mesma formação ou configuração social.

Ademais, pelo exposto até aqui, constata-se que as pesquisas do campo da história do tempo presente têm uma "peculiar pertinência a aspiração à verdade” que é própria da pesquisa histórica e, particularmente, da história da educação. Concordamos com Chartier quando afirma que “a história do tempo presente, mais que todas as outras, mostra que há entre a ficção e a história uma diferença fundamental que consiste na ambição da história de ser um discurso verdadeiro, capaz de dizer o que realmente aconteceu. Essa vocação da história, que é ao mesmo tempo narrativa e saber, adquire especial importância quando ela se insurge contra os falsificadores e falsários de toda a sorte que, manipulando o conhecimento do passado, pretendem deformar as memórias” (ibidem, p.217-218). Com outras palavras, a história da educação do tempo presente nos propicia compreender as condições e as incertezas dos processos de produção e de validação do conhecimento histórico e exige que a busca da verdade seja pressuposta sine qua non da própria existência da pesquisa e dos pesquisadores da educação e de sua história. Deste prisma, Foucault (1979) também nos ajuda a pensar nas práticas dos historiadores da educação (enquanto intelectuais) e especialmente quanto às suas condições de trabalho e quanto à produção de discursos que tenham como caminho fundante e principal o não falseamento da verdade, apesar da organicidade social (antes alertada por Gramsci, 1982) que é inerente à sua própria condição de intelectual.

\section{Fontes da história da educação do tempo presente}

A multiplicação das fontes de pesquisa da história da educação do tempo presente tem sido relevante e conferido a este tipo de pesquisa uma possibilidade concreta de aproximação mais vigorosa à verdade histórica. Agregado ao fato de que o historiador do tempo presente tem um olhar de 
raio mais curto e por isso mesmo está mais atento à pluralidade dos detalhes, às contingências e aos acasos da história, o trabalho com as fontes tem constituído uma das principais fortalezas das pesquisas do contemporâneo em educação e tem multiplicado seu alcance e aplicação tanto na história como nas demais ciências sociais e, ainda, nas confluências da história com essas demais ciências. Dos avanços da iconografia às novas tecnologias da informação, passando pelo jornalismo instantâneo, as fontes históricas do tempo presente se multiplicaram e impactaram a pesquisa histórica redimensionando-a.

Dentre as fontes de pesquisa mais utilizadas e que têm demonstrado mais eficácia destacamos as fontes orais da história da educação do tempo presente. Não é demais relembrarmos a argumentação inicial deste trabalho quando nos referimos à necessidade de contarmos com as versões e as representações dos que fazem a prática educacional como fator preponderante e cuidadoso da própria pesquisa em educação. Ouvir e dialogar com os atores e atrizes das práticas educacionais tem se mostrado absolutamente importante para as pesquisas do cotidiano da educação em suas múltiplas modalidades e nos seus diversos graus. Certamente, neste sentido, as fontes orais têm se revelado com aliadas indispensáveis dos pesquisadores do tempo presente (Alberti, 2004), mesmo quando não são identificadas ou caracterizadas como tais, seja por falta de maior conhecimento deste campo, seja porque se encontram caracterizadas como tradicionais entrevistas que há tanto tempo permeiam as investigações em educação e em pedagogia. De todo modo, a abundante presença (quase permanente) das gravações de depoimentos de alunos, professores, gestores etc. no terreno dessas investigações, continua a revelar a importância crescente dessas fontes. O fato de que, nos encontros de pesquisa das diversas ciências sociais, inclusas as chamas ciências da educação, as fontes orais (ou a chamada história oral) tenham se constituído em importante aparato das pesquisas qualitativas também nos faz constatar sua estratégica presença.

No nosso caso específico em tela, contar com as fontes orais tem sido 
de suma importância por todos os argumentos que já foram enunciados e por outros que a brevidade de um trabalho com este não nos permite alongar.

Isto se dá, basicamente, porque “abordar o fenômeno da oralidade é ver-se defronte e aproximar-se bastante de um aspecto central da vida dos seres humanos: o processo de comunicação, o desenvolvimento da linguagem, a criação de uma parte muito importante da cultura e esfera simbólica humana” (Lozano, 1996, p.15). Ora, comunicação, linguagem, cultura e esfera simbólica são constituintes da própria formação humana, ou seja, da educação. Concordamos com Lozano quando afirma que

\begin{abstract}
A história oral é um espaço de contato e influência interdisciplinar; social, em escalas e níveis locais e regionais; com ênfase nos fenômenos e eventos que permitam, através da oralidade, oferecer interpretações qualitativas de processos histórico-sociais. Para isso conta com métodos e técnicas precisas, em que a constituição de fontes e arquivos orais desempenha um papel importante. Dessa forma, a história oral, ao se interessar pela oralidade, procura centrar a sua análise na visão e na versão que emanam do interior e do mais profundo da experiência dos atores sociais (ibidem, p.16).
\end{abstract}

E, certamente, por isso é fundamental alicerce da educação do tempo presente e da sua história. Acrescentamos o fato de que num país de baixa escolaridade, no qual milhões de crianças, jovens e adultos comunicam-se quase que exclusivamente pela via da oralidade, a pesquisa da história da educação da grande maioria da nossa população não pode prescindir desse fundamento teórico-metodológico. Ademais, a carga de subjetividade humana presente em todas as práticas sociais constitui uma das centralidades da pesquisa e da produção de conhecimentos históricoeducacionais, inclusa a ampla diversidade das histórias da educação popular.

No entanto, não podemos concordar com a idéia de que a história oral é uma "outra” história. Deste prisma, os argumentos de Etienne François (1996) são convincentes:

Nos países germânicos, especialmente, a história oral é vista como uma história diferente, tanto em seus objetos como em suas práticas, de história 'alternativa', livre e emancipadora, em 
ruptura com a história acadêmica institucional. Para justificar tal visão: $\left(1^{\circ}\right)$ a história oral seria inovadora primeiramente por seus objetos, pois dá atenção especial aos "dominados", aos silenciosos, aos "excluídos” da história (mulheres, proletários, marginais, analfabetos...), à história do cotidiano e da vida privada, à história local e enraizada. $\left(2^{\circ}\right)$ Seria inovadora por suas abordagens que dão preferência a uma "história vista de baixo" atenta à maneira de ver e sentir e que às estruturas "objetivas" e às determinações coletivas prefere as visões subjetivas e os percursos individuais, numa perspectiva decididamente "micro-histórica". Entretanto, reparando melhor, nenhuma das razões alegadas para justificar a pretensão da história oral a ser uma "outra" história - e que de tão repisadas quase se tornaram banais - resiste a um exame de especificidade. De fato, longe de ser própria da história oral, a atenção dada a novos objetos e à adoção de novas abordagens são, pelo contrário, observadas muito além dos seus limites (...) e constituem apenas um aspecto entre outros das redefinições metodológicas e das mutações internas da pesquisa histórica atualmente em curso" (p.4-6).

Ainda seguindo a autora, podemos dizer que a história oral deve parte do seu sucesso atual "ao fato de ter sabido adaptar à história do tempo presente e às problemáticas e aos métodos desenvolvidos pelo que ainda há pouco chamávamos de nova história”. E, assim, não podemos afirmar que a história oral é uma “outra” história.

Neste sentido, parece-nos correta a afirmativa de Lozano (1996):

A história oral compartilha com o método histórico tradicional as diversas fases e etapas do exame histórico. De início, apresenta uma problemática, inserindo-a num projeto de pesquisa. Depois, desenvolvemos procedimentos heurísticos apropriados à constituição de fontes orais que propôs a produzir. Na hora de realizar essa tarefa, procede, com o maior rigor possível, ao controle às críticas interna e externa da fonte constituída, assim como das fontes complementares e documentais. Finalmente, passa à análise e à interpretação das evidências e ao exame detalhado das fontes recompiladas ou acessíveis (p.16).

Assim, utilizando a oralidade como uma das suas fontes principais, os historiadores da educação do tempo presente não apenas registram a história vista de baixo, ou “dão voz” aos que não a possuem, e nem fazem com que suas capacidades de pesquisar sejam substituídas pela gravação. Mergulham por inteiro na análise histórica e, ao considerar a fonte 
oral na educação per si e não meramente ilustrativa, têm condições concretas de criticar a própria produção da fonte pesquisada. E não ficam por aí: buscam outras fontes, apostam na interdisciplinaridade, aproximamse das ciências sociais/humanas, enfim, têm um olhar crítico sobre a relação do pesquisador da educação do tempo presente com os problemas, os sujeitos e as incertezas da sua pesquisa.

Temos que destacar, ainda, com Lozano, especialmente quando pensamos a pesquisa educacional contemporânea, que

De certa forma, o historiador oral que tende a integrar todas essas práticas, está em busca do seu passado e ao mesmo tempo de sua identidade. Neste estilo de trabalho, a tarefa de produzir conhecimentos históricos se torna válida e especialmente rica e atual, já que implica: reflexão teórica; trabalho empírico e de campo; maior ligação e vínculo pessoal com os sujeitos estudados; um processo de constituição de uma fonte e um processo de produção de conhecimentos científicos, isto é, um processo que permite ao pesquisador se transformar no que sempre pretendeu ser, um historiador. (ibidem, p.24).

Com efeito, as fontes orais do tempo presente, além de se imiscuírem na concreticidade de uma prática social (como a educação) de modo ímpar, além de provocarem as pesquisas de novos objetos contando com uma nova documentação, transcendem as relações com os arquivos e com os documentos sem vida, se aproximam como nenhuma outra fonte dos sujeitos da educação. Mas, nem por isso, esquecem dos perigos, dos percalços, dos “usos e dos abusos” de todas as fontes da pesquisa histórica.

Em suma, se as fontes orais da contemporaneidade propiciam tantos avanços nas pesquisas histórico-educacionais, como bem assinala François (1996), “é porque seu potencial heurístico vai além dos aperfeiçoamentos técnicos de uma simples 'ciência auxiliar', podendo, desde que utilizado com conhecimento de causa, desembocar num verdadeiro salto qualitativo” (p.9). E, talvez, nenhuma outra fonte histórica consiga evidenciar a proximidade da pesquisa empírica e da reflexão teórica com os métodos e os problemas (e seus sujeitos), além de demonstrarem cabalmente que a 
produção historiográfica é sempre elaborada pelo pesquisador e que a história não é resgate, mas, sim, (re)construção.

\section{Uma nova epistemologia da história da educação}

Como conseqüência do que foi exposto, temos que destacar o esforço de construção de uma nova epistemologia da história da educação. E, também, reconhecer que este esforço tem pontos de partida localizados inflexão na Escola dos Annales e na "nova história”.

Desta perspectiva, temos que considerar que o tempo histórico é marcado por um pluralismo e uma descontinuidade que evita e livra a história da educação e da pedagogia de dois equívocos: a tomada do passado como algo "morto" adaptado ao presente e o presente como ponto de chegada do passado - do qual é apenas uma das possibilidades.

O que foi argumentado nos leva a ratificar a visão da pesquisa histórico-educacional de forma também plural, articulada entre a história da pedagogia, da educação, da instituição escola, da política e do cotidiano escolar, das metodologias, dos hábitos educacionais, da legislação educacional etc. Essa pluralidade, inclusive, não nos deixa, em definitivo, separar a história da educação da história da pedagogia, a reflexão teórica e os fatos educativos.

Por outro lado, as incertezas, a pluralidade e a descontinuidade histórica, além do posicionamento fronteiriço dessa história que coloca sua necessidade interdisciplinar como parte fundante da sua própria existência, ratificam alguns pontos básicos dessa tendência historiográfica da educação. Entre eles se destacam: (1) a necessidade de ampliação das problemáticas de pesquisa; (2) o crescente espaço da problematização no lugar da narrativa; (3) a ampliação dos arquivos e da documentação que inclui os questionários e os depoimentos dos atores educacionais; (4) a recuperação das fontes imaginárias e silenciadas, especialmente as inerentes às camadas subalternas; (5) o abandono da linearidade e a consideração dos percalços e dos acasos da história e (6) os paralelos e as convergências dos tempos 
curtos e longos da história educacional.

Com efeito, no recente processo de construção destes caminhos, principalmente considerando os avanços da pesquisa histórico-educacional brasileira, aos "novos historiadores da educação" pode-se creditar o trincamento da noção petrificada de que a pesquisa histórico-educacional e pedagógica coincidia com a história do pensamento e da instituição escolar, a abertura e a incorporação das teorizações das outras ciências sociais/humanas, as novas temáticas do imaginário, das mentalidades, do cotidiano e das subjetividades educacionais.

Outro fator determinante das preocupações epistemológicas dessas pesquisas foi a assunção da necessidade imperiosa de contar com teorizações especificamente educacionais e pedagógicas, escolares ou não, para enfrentar a pesquisa de natureza histórica. Como bem argumenta Geovanesi (1994),

Inexiste "o histórico", mas historicidades de vários âmbitos disciplinares cada um possuindo quadros sólidos de referências teóricas. Como é possível enfrentar uma investigação histórica sobre a escola, sem ter posse de uma teoria da escola? Esta última é indispensável para formular a assunção teórica, ou prototeórica (...) que permite que a pesquisa indique o que pesquisar e alargando as possibilidades de sistematização orgânica do paradigma conceitual, sempre mais defensável através do momento da indução. E, por outro lado, uma teoria da escola é indispensável ainda, para incrementar outros setores da historiografia educativa que trabalha o aspecto puramente escolar, (...) para enfrentar o exame de outros fatores formativos ou, pelo menos, fortemente incidentes em sua formação, como, por exemplo, a questão instrução/formação e ideologia, as condições da vida familiar e extrafamiliar do sujeito nesta evolução, a imagem da escola hegemônica num determinado período como vem descrita na narrativa, na memória, do ensino oficial e da administração escolar e, ainda, o setor do tempo livre, do jogo, da literatura infantil, (...) de várias teorias da aprendizagem influenciadas pela formação escolar ou extraescolar (p.10-11).

Certamente, embora não seja fácil arregimentar a metodologia histórica básica com a teorização educacional/pedagógica essa tarefa se impõe. Se a certificação do educativo não satisfaz per si sua historicidade, torna-se imperiosa a individualização teórica do objeto pesquisado do ponto 
de vista do educativo/pedagógico.

Devemos concordar com Geovanesi (1994) quando, coloca que,

O histórico da educação reconstrói um "mapa da instrução e da educação", no qual o pesquisador não pode, de principio, deixar na sombra nenhum setor societário, pluralizando o objeto histórico-educativo (escola, método, instrumentos, seqüência didática, instituição, teoria, estratégias educativas, folclore etc.) e conseqüentemente a orientação metodológica voltada para a micro-história e a história oral, superando assim definitivamente as limitações das instituições educativas e a pedagogia oficial, mas deve tratar de fazer uma "história dos mecanismos da educação" examinando as várias datas, recortadas segundo um observatório educativo (p.11).

Por isso mesmo, acerta este autor quando defende que "não se pode deixar de prestar uma atenção particular a todas aquelas intervenções e aqueles acontecimentos que o pesquisador pensou logicamente ter representado um esforço de emancipação moral e material das classes subalternas ou, comunitárias, de todos os sujeitos marginalizados do circuito oficial de formação, até a própria capacidade de recuperação da formação de tais sujeitos por parte da 'mentalidade' das várias épocas que constituíam sinais de um clima educativo em uma determinada sociedade” (ibidem, p.12).

Certamente, a consideração de todos os aspectos dessa história “total” torna-se fundamental para a pesquisa histórico-educacional. E poucos ramos dessa pesquisa têm condições de implementá-la como a história da educação e da pedagogia do tempo presente. Sua abundância de fontes e de teorias desafia os historiadores a investirem seus esforços na consecução e no aprofundamento dos seus achados, descobertas e (re)construções. Sua importância estratégica para o próprio status científico desse campo de pesquisa - que implica e respalda, inclusive, o status de cientificidade da pesquisa educacional como um todo -, requer maior aplicabilidade e maior relevância no rol das pesquisas das ciências humanas/sociais. Tal fato reforça a consideração da relevância desse campo da pesquisa histórica 
(crescentemente adotado pelas demais ciências sociais/humanas) e demonstra a pertinência da batalha por uma história da educação e da pedagogia do tempo presente.

\section{Considerações finais}

Procuramos argumentar neste trabalho que a inseparabilidade presente-passado reforça a importância atribuída à história do tempo presente tanto em si mesma quanto como ponto de partida da regressão à história do tempo passado. Neste sentido, buscamos demonstrar a validade e a especificidade da história do tempo presente, bem como sua pertinência enquanto história de uma duração (e, não, da instantaneidade) que impacta a história do passado de maneira irreversível. Com Chartier, destacamos a abundância de suas fontes de pesquisa e, por conseqüência, sua peculiar pertinência à aspiração da verdade histórica. Ainda em relação às fontes da história da educação do tempo presente, enfatizamos a singular contribuição das fontes orais, especialmente no campo educacional que requer sobremaneira os depoimentos e os testemunhos dos que fizeram/fazem a prática educativa. Defendemos a idéia segundo a qual sem contarmos com as informações e os depoimentos dos que praticam a educação dificilmente poderíamos desvendá-la em sua inteireza e complexidade. Ao mesmo tempo, a abundância das fontes da história da educação do tempo presente não nos remete a uma maior facilidade de investigação, ao contrário, nos reforça a clareza de que as incertezas, a pluralidade e a descontinuidade continuam a marcá-la e a exigir que os historiadores da educação se preocupem em elaborar uma epistemologia condizente com os percalços da pesquisa e com a necessidade incessante da busca de uma verdade histórica cada vez mais fugidia. Não deixa de ser paradoxal a constatação de que a crescente disponibilidade de fontes históricas da educação do tempo presente, e regressivamente da história da educação do passado, caminha paralela à busca de um maior rigor científico das investigações e que esse 
rigor encontra-se contextualizado por uma crise teórico-metodológica sem precedentes nas ciências humanas e sociais.

\section{Referências}

ALBERTI, V. (2004). Manual de história oral. Rio de Janeiro: Editora da FGV.

AMADO, J. (org.) Usos e abusos da história oral. Rio de Janeiro: Editora da FGV, p. 215-224.

CHARTIER, R. (1990). História cultural - entre práticas e representações. São Paulo: DIFEL.

CHARTIER, R. (1996). "A visão do historiador modernista", IN: FERREIRA, M. e AMADO, J. (org.) Usos e abusos da história oral. Rio de Janeiro: Editora da FGV.

ETIENE, F. (1996). "A fecundidade da história oral”, IN: FERREIRA, M. e AMADO, J. (org.) Usos e abusos da história oral. Rio de Janeiro: Editora da FGV, p. 3-13.

FERREIRA, M. e AMADO, J. (org.) (1996). Usos e abusos da história oral. Rio de Janeiro: Editora da FGV.

FOUCAULT, M. (1979). Microfísica do poder. Rio de Janeiro: Graal.

GEOVANESI, G. (1994). La storiografia dell'educarione oggi - linee di tendeña e problemi. Campinas: II Congresso Ibero-americano de História da Educação Latino-americana - UNICAMP, mimeo.

GRAMSCI, A. (1982). Os intelectuais e a organização da cultura. Rio de Janeiro: Civilização Brasileira.

LE GOFF, J. (1992). História e memória. Campinas: Editora da Unicamp.

LOZANO, J. (1996). "Prática e estilos de pesquisa na história oral contemporânea", IN: FERREIRA, M. e AMADO, J. (org.) (1996). Usos e abusos da história oral. Rio de Janeiro: Editora da FGV, p.15-25.

RÉMOND, R. (1996). "Algumas questões de alcance geral à guisa de introdução”, IN: FERREIRA, M. e AMADO, J. (org.) (1996). Usos e abusos da história oral. Rio de Janeiro: Editora da FGV, p.206-214. 